\title{
Teleodontología: Desarrollo y Gestión de la Telesalud en la Odontología
}

\author{
Teledentistry: Development and Management of Telehealth in Dentistry
}

\author{
Jorge Enrique Manrique Chávez ${ }^{1,2, a, b, c, d,}$
}

A lo largo de los años, mediante la incorporación de las Tecnologías de la Información y la Comunicación (TIC) al campo de la salud, conceptos como Informática en Salud, Informática Biomédica, Salud Digital, Salud Móvil, Telesalud y Telemedicina, se han desarrollado a través de propuestas tecnológicas e iniciativas informáticas en los sistemas de atención a nivel público y privado. Durante este proceso de crecimiento tecnológico y diversificación informática, la Universidad Peruana Cayetano Heredia (UPCH) ha liderado proyectos que abordan líneas de investigación en Informática en Salud o Biomédica, así como programas de intervención en salud pública y salud global con enfoque en la eSalud (mHealth), Salud Digital y/o Salud Móvil y programas académicos de pregrado (Ingeniería Biomédica e Ingeniería Informática) y de posgrado (Informática Biomédica en Salud Global con mención en Informática en Salud o en Bioinformática). Todo esto empleando los fundamentos de las ciencias básicas y de las ciencias de la vida, las bases esenciales de la salud pública y salud global y los principios de la informática para abordar la problemática en salud a través de soluciones innovadoras, aplicativos útiles para la salud de los individuos, de la familia y de la comunidad, productos tecnológicos enfocados a elevar la calidad de vida de las personas y de la sociedad, así como contribuir a la transformación digital de la salud en el país.

Por todo ello, se reafirma que la Informática en Salud y Telesalud se constituyen como elementos a incorporar en las mallas curriculares y planes de estudios de las carreras y programas de las ciencias de la salud con el objetivo de promover el uso de la tecnología basada en la evidencia para beneficio de la población bajo los principios de universalidad, equidad, eficiencia, calidad del servicio, descentralización y desarrollo social, así como fortalecer la práctica profesional con el objeto de reducir las brechas de accesibilidad a los servicios, humanizar la práctica de la salud digital, responder en forma oportuna a las necesidades esenciales de los individuos durante todo el curso de vida y reorientar los servicios hacia la prevención y promoción de la salud con el uso de las TIC.

En tal sentido, conceptos como la Teleodontología e Informática Odontológica, ambos reconocidos dentro de los Descriptores en Ciencias de la Salud (DeCS) de la Organización Mundial de la Salud (OMS) y de la Organización Panamericana de la Salud (OPS), han de ser incorporados con mayor énfasis en la práctica del Cirujano Dentista para su desarrollo profesional en un entorno competitivo, el cual afronta nuevos retos mundiales debido al proceso de globalización orientado hacia la Transformación Digital, la Cuarta Revolución Industrial

\footnotetext{
Sección Académica de Salud Pública y Gestión de Servicios Odontológicos del Departamento Académico de Odontología Social, Facultad de Estomatología Roberto Beltrán, Universidad Peruana Cayetano Heredia. Lima, Perú.

Instituto de Salud Oral (ISO). Lima, Perú.

Docente ; ORCID ID: https://orcid.org/0000-0002-5119-5405
} 
(Industria 4.0) y las Megatendencias en Salud. Por tanto, es necesario reforzar y delimitar una definición de Teleodontología, no sólo con el fin de aplicar y replicar los estándares, criterios y conceptualizaciones de organismos gubernamentales y científicos internacionales, sino para, principalmente, contar con una herramienta que permita su incorporación e inclusión en el marco de la Agenda Digital del Sector Salud 2020-2025 -R.M. 816-2020/MINSA(1) y permitir su operativización como parte del Plan Nacional de Telesalud del Perú 20202023 -R.M. 1010-2020/MINSA (2).

La Teleodontología se establece como un canal de monitoreo de las atenciones y de prestación de servicios odontológicos realizados a distancia, lo cual permite acercar las necesidades del paciente a la atención y generar propuestas terapéuticas eficaces y oportunas, así como contar con diagnósticos especializados. A través de ésta se puede asesorar u orientar al paciente o familiares de éste, mediante información y consejos sobre el cuidado de la salud bucal, así como realizar seguimiento continuo de un conjunto de tratamientos o cuadros clínicos y definir con el paciente si es necesaria una visita al consultorio odontológico (figura 1).

Por otro lado, la Teleodontología tiene el potencial de contribuir en la forma en que se desarrolla la industria dental, así como el modo en que los usuarios de salud ven la experiencia odontológica; además, permite la atención preclínica con el fin de definir el mejor momento para retomar o acudir a la consulta presencial ya que promueve una consulta híbrida (presencial y virtual) según el caso y la condición de cada paciente, permitiendo la evaluación, diagnóstico, terapéutica, seguimiento y/o control según sus necesidades y limitaciones. De manera complementaria, permite establecer, incentivar y/o mantener la relación odontólogo-paciente en tiempo real (sincrónico) o en tiempo diferido (asincrónico) por medio de llamadas telefónicas, mensajes de voz, envío de imágenes $\mathrm{o}$, de preferencia, a través de una videollamada o videoconferencia, en la cual el paciente puede absolver consultas que no requieren de una visita al consultorio.

Adicionalmente, la Teleodontología permite fortalecer el enfoque de la Odontología Preventiva, propiciando una mayor información sobre los cuidados de la salud bucal a los pacientes, así como de los beneficios de la amplia cartera de servicios de forma oportuna con una filosofía mínimamente invasiva, además, de exponer las múltiples posibilidades de las diferentes disciplinas o especialidades estomatológicas. Además, contribuye a promover
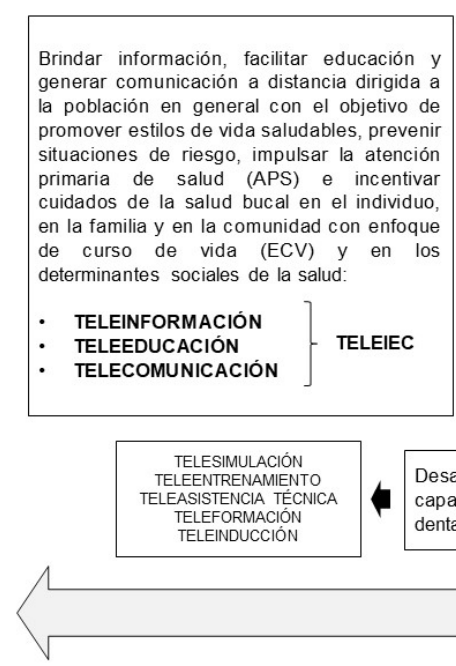

TELEAPOYO AL DIAGNÓSTICO

Figura 1. Modelo de desarrollo y gestión de la Teleodontología acorde al marco legal y normativo de la Telesalud en el Perú y a las tendencias internacionales. 
una correcta salud bucal y hábitos saludables sin contacto físico, a través de consultas mediante aplicativos de mensajería (SMS), correos electrónicos, teléfonos móviles (smartphones), dispositivos electrónicos, equipos de computación o plataformas para videoconferencias/videollamadas.

Sin embargo, la Teleodontología debe cumplir con todos los principios éticos, legales y normativos para garantizar un adecuado Acto de Salud o Acto Estomatológico, por tanto, toda comunicación a través de ésta debe ser realizada por profesionales Cirujanos Dentistas titulados, colegiados y habilitados para el ejercicio profesional, así como que todo servicio, consulta u orientación que se realice, debe registrarse en la historia clínica del paciente para dejar documentada la atención y evidenciar la relación Odontólogo-Paciente. Asimismo, esta práctica abre una amplia variedad de herramientas que permitirían su complementación y fortalecimiento, por ejemplo, el uso y gestión de una Historia Clínica Electrónica (HCE), la prescripción odontológica mediante una Receta Única Estandarizada Informatizada, la emisión de informes y/o certificados odontológicos con Firma Digital, el apoyo al diagnóstico mediante fotografía clínica, cámaras intraorales, radiovisiografía (RVG), entre otras aplicaciones.

Por todo lo antes expuesto, la Teleodontología se ha de emplear como una extensión de la práctica odontológica tradicional ya que no reemplaza a la consulta o atención presencial, por el contrario, la complementa. A través de ésta se puede proveer y mejorar el acceso a la información y atención especializada de poblaciones que se encuentren aisladas o que, por factores geográficos, carezcan de especialistas para realizar consultas, interconsultas o acceder a segundas opiniones. La Teleodontología se expresa como una alternativa segura, siempre y cuando cumpla con los parámetros de seguridad informática (ciberseguridad) y de privacidad de datos, así como cómoda y práctica para obtener orientación sobre la atención dental sin provocar ansiedad, estrés o miedo de acudir al consultorio y limitar su exposición a factores de riesgo biológico, por lo que es útil para orientar a los usuarios de los servicios de salud y continuar la consulta a través de un sistema de triaje que permita priorizar las atenciones y generar valor agregado a la práctica odontológica del siglo XXI, contemporánea, tecnológica y digital, pero, por sobre todo, sostenible, humana y ética.

\section{Correspondencia:}

Jorge Enrique Manrique Chávez

Jirón Pedro Martinto 114, Barranco. Lima-Perú.

Teléfono: (51) 987703140

Correo electrónico: jorge.manrique.ch@upch.pe

\section{REFERENCIAS BIBLIOGRAFICAS}

1 Ministerio de Salud. Resolución Ministerial Nº8162020/MINSA. Lima; Ministerio de Salud; 6 de octubre del 2020. (Citado el 25 de julio del 2021) Disponible en: https://cdn.www.gob.pe/uploads/document/ file/1362855/RM\%20816-2020-MINSA.PDF.PDF

2 Ministerio de Salud. Resolución Ministerial N${ }^{\circ} 1010$ 2020/MINSA. Lima; Ministerio de Salud; 9 de diciembre del 2020. (Citado el 25 de julio del 2021) Disponible en: https://cdn.www.gob.pe/uploads/ document/file/1479230/Resoluci\%C3\%B3n\%20 Ministerial\%20N\%C2\%B01010-2020-MINSA.PDF 